UPGRADING THE STRAIN HARDENING CAPACITY AND ABRASION

RESISTANCE OF MANGANESE STEEL ALLOY

\author{
WALEED ELGHAZALY ${ }^{1}$, SAYED HASSAN ${ }^{2}$ \& SAIED ELGHAZALY ${ }^{3}$ \\ ${ }^{1}$ Reseacher, Steel Technology Lab, Central Metallurgical R\&D Industrial (CMRDI), Helwan, Egypt \\ ${ }^{2}$ Production Engineer, Siegwart Co, Helwan, Egypt \\ ${ }^{3}$ Emeritus Professor, Central Metallurgical R\&D Industrial, Helwan, Egypt
}

\begin{abstract}
Resistance against gouging and abrasive wear in impact crushing arms cast from Mn-steel, is related to variations of carbon, manganese and the microstructure of the cast steel. Additions of Boron, molybdenum and chromium to the plain Mn-steel casts $(0.8-1.4 \% \mathrm{C}-13 \% \mathrm{Mn})$ increase its wear resistance and fatigue life time during crushing operation due to enhancement of its strain hardeing capacity, grain refinement and strengthening by solid solution hardening of the matrix. This improvement is due to the intended change in the microstructure where precipitation of boron carbides and chromium carbides inside the austenitic matrix, grain refinement and increasing soluble carbon content in austenite phase is occurred. Solution treated $\mathrm{Mn}$-steels $\left(105^{\circ} \mathrm{C} 0,2 \mathrm{~h}, \mathrm{WQ}\right)$ alloyed with boron showed crushing capacity of about 600-850 tones basalt per set depending on their compositions. The hardness of the as water quenched austenite is increased by about $25 \%$ to reach $397 \mathrm{HB}$ when alloyed with $0.37 \%$. However work hardened matrix of $\mathrm{Cr}+\mathrm{Mo}+\mathrm{B}$ modified Mn-steel impact arms showed a bulk hardness of about 498 HB. The fatigue resistance of boron alloyed steel is increased to about 1.4 times over that measured for plain Mn-steel.

KEYWORDS: Manganese Steel, Abrasion Resistance, Work Hardening Capacity, Wear and Gouging Resistance \& Second Phase Fine Carbides
\end{abstract}

Received: Mar 19, 2019; Accepted: Apr 09, 2019; Published: May 07, 2019; Paper Id.: IJMPERDJUN201973

\title{
INTRODUCTION
}

Manganese steel has an austenitic matrix that posses high toughness and high wear resistance as a result of its high hardening rate in polycrystalline structure. The technology of manufacturing reinforced concrete railway slippers depends to a great extent on the specifications of the raw materials feed used. Basalt is one of the major materials which is used as slippers strengthener. The raw basalt rocks are primarily crushed to coarse lumps in a jaw crusher and then fed to a rotary impact crusher for further reduction in size. $13 \%$ manganese steel arms are used in that crushers where severe gouging and abrasion wear take place.

The mechanical properties required from impact arms comprise excellent combinations of abrasion resistance, gouging wear and good impact toughness [1, 2]. The usual way to increase the abrasion resistance of any material is to raise its hardness [3]. This usually leads to a reduction in the fracture toughness of the material and causes in many cases catastrophic failure of the system. However, the $13 \% \mathrm{Ma}$-steel is characterized by high strength, impact toughness and excellent work hardening capacity during heavy impacts [4,5]. This steel is an austenitic one in which the usual hardening transformation has been suppressed due to the presence of high manganese content and the rapid cooling rate from austenitizing temperature[6]. Manganese 
plays an important role in the hardening process of that steel hence it shifts the isothermal transformation curve to the right and changes the eutectoid point to occur at $0.25 \% \mathrm{C}$ at $13 \% \mathrm{Mn}$. Manganese also decreases the transformation temperature of austenite to martensite (Ms), this ensures a fully austenitic structure even at room temperature. There are many difficulties in casting manganese steels arise from its low thermal conductivity, the basicity of its slag during melting (high $\mathrm{MnO} \%$ ) and the severe segregation of carbides ( $\mathrm{Fe} 3 \mathrm{C}$ ) and $\mathrm{Mn} 3 \mathrm{C}$ to prior austenite grain boundaries. Accordingly, care must be taken during designing gating and riser system and even during handling the heavy castings in order to prevent thermal stress cracking due to cooling in the mould and cleaning [7]. Performance of manganese steel depends to a great extent on choosing the correct production technology of making, casting, and heat treating such steels.

The aim of this research is to examined the performance of many impact arms of the rotary crusher having variable chemical compositions, microstructures, and matrix grain refinement. The gouging and abrasion wear of the impact arms were measured in relation to matrix parameters, work hardening and steel composition.[8-10].

\section{EXPERIMENTAL MATERIALS}

Manganese steels were produced in coreless medium frequency 1.5tons induction furnace. Both the furnace and ladle were lined with basic magnesite lining. Carbon steel scrap, foundry returns and carburizer were charged into the furnace as raw materials. After melting and deslagging new slag forming oxide materials $(\mathrm{CaO}, \mathrm{CaF}, \mathrm{CaSi})$ were fed to the melt in order to accomplish deoxidation by diffusion and precipitation. Ferro-manganese 4 and other alloying elements such as ferrochromium, ferromolybdenum and ferroboron were then added to the melt. The chemical composition of steel was adjusted in the very final stages of melting before pouring. Table (1), summarizes the composition and hardness of different steel casting produced in this investigation

Table 1: Chemical Composition and Hardness of Produced Modified Mn- Steel

\begin{tabular}{|l|c|c|c|c|c|c|}
\hline Heat & C & Mn & Cr & Mo & B & Si Hardness of Austenite, HB \\
\hline P1 & 0,81 & 13,05 & & & & 0,65230 as WQ / 338 strained \\
\hline P2 & 1,22 & 13,12 & & & & 0,71275 as WQ / 318 strained \\
\hline P3 & 1,42 & 12,98 & & & & 0,64295 as WQ / 321 strained \\
\hline M1 & 1,34 & 13,05 & 1,26 & 1,03 & & 0,72310 as WQ / 352 strained \\
\hline M2 & 1,29 & 13,12 & 1,56 & 1,25 & & 0,69325 as WQ / 365 strained \\
\hline B1 & 1,28 & 13,06 & 1,61 & 1,19 & $\underline{0,11}$ & 0,72350 as WQ / 395 strained \\
\hline B2 & 1,31 & 12,98 & 1,71 & 1,21 & $\underline{0,25}$ & 0,67385 as WQ / 435 strained \\
\hline B3 & 1,29 & 12,16 & 1,68 & 1,16 & $\underline{0,37}$ & 0,62397 as WQ / 498 strained \\
\hline
\end{tabular}

\section{HEAT TREATMENT}

Like all austenitic steels, the standard treatment that produces normal tensile properties and the desired toughness is the solution annealing and quenching. Because manganese steel has lower thermal conductivity and higher thermal expansion, sudden heating during heat treatment may cause severe cracking in the castings. Accordingly, the castings are charged in a cold furnace before heating at a rate of about $150^{\circ} \mathrm{C} / \mathrm{h}$ maximum.

Preheating at $700 \mathrm{C}$ for 2 hours is necessary to remove any sudden thermal stresses within the casting of impact arms, Figure (2).

The castings are left at about $1050^{\circ} \mathrm{C}$ for $1-2$ hours

(Depending on their thickness) and then water quenched immediately without any further tempering. 


\section{RESULTS AND DISCUSSIONS}

The slow cooling of impact arm castings during solidification from $1420^{\circ} \mathrm{C}$ permits nucleation and growth as well as segregation of primary carbides (hypereutectic carbides) to austenite grain boundaries. Presence of $13 \%$ manganese stabilizes the austenite and depresses the temperature at which martensite starts to form down to ambient temperature as shown in Figure (1). Iron-manganese carbides (FeMn)3C are observed in the as cast -plain Mn steel, however, chromium, molybdenum and boron- carbides $(\mathrm{FeCr}) 3 \mathrm{C}$ and $(\mathrm{FeMoB}) 3 \mathrm{C}$ are also observed specially in alloyed Mn steel, however some fine carbides of boron (secondary carbides) are also detected inside austenite grains. The as cast structures of steels containing molybdenum and boron are more or less finer with less carbide segregations than that of plainmanganese steels, this is attributed to the fact that Mo and B carbides hinder the grain growth and segregation of the matrix and the dissolved Mo-B in the austenite matrix lower the activity of carbon and preventing it from segregation to grain boundaries as shown in Figure (3).

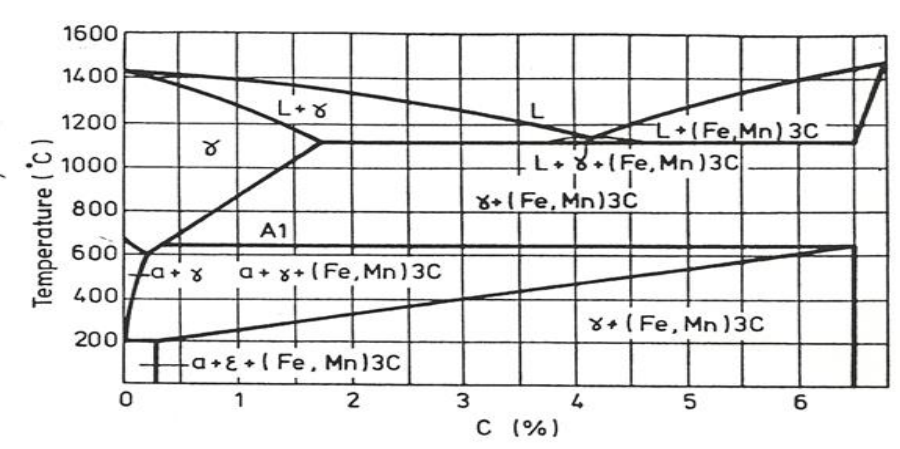

Figure 1: Iron-Carbon Equilibrium Diagram at 13\% Manganese

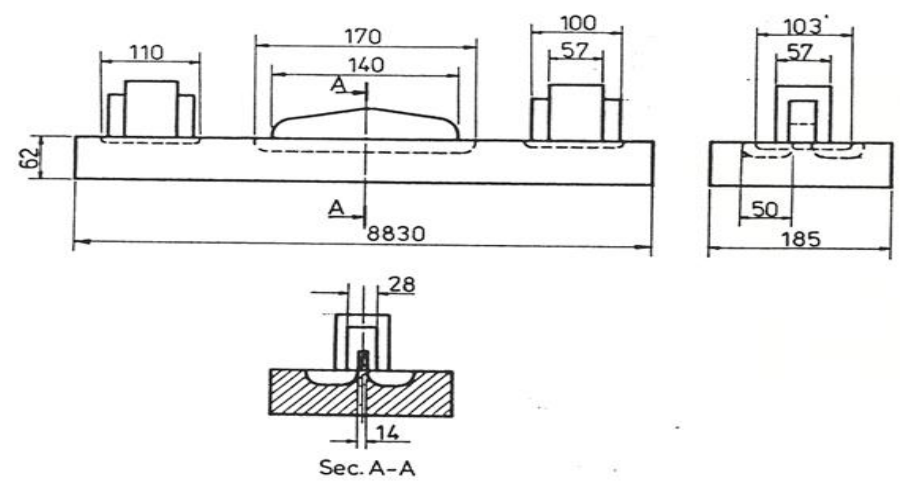

Figure 2: Configuration of the Impact arm of Basalt Rotary Crusher

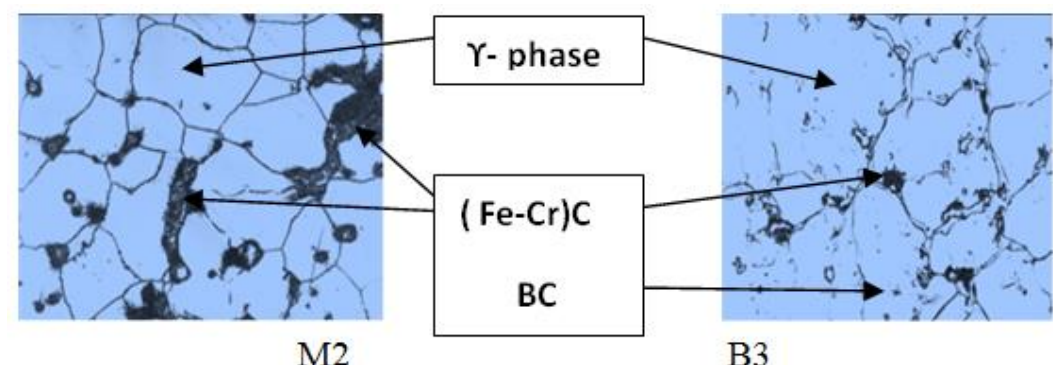

Figure 3: As Cast Structures of M2 and B3, 300X 
Precipitation of primary carbides (FeMn) $3 \mathrm{C}$ at austenite grain boundaries make the manganese steel brittle and cannot withstand the repeated impacts during crushing basalt. The performance of as cast plain manganese impact arms during crushing basalt as compared with those cast from Cr-Mo-B manganese steels is projected as in Figure (4).

The impact arms as cast from plain $\mathrm{Mn}$ or Mo+Cr or Mo-Cr-B steel alloys withstand crushing efficiency of 150 to 280 tones, however manganese steel alloyed with $0.37 \%$ boron withstands crushing life time equal to 850 tones basalt.

Quench annealing of cast impact arms produces austenitic steel matrix without any carbide precipitation at grain boundaries, thus producing tough steel matrix as depicted in Figure (5).

Manganese steels of composition B1, B2 and B3 have increasing tensile strength and elongation of about 600 MPa and $40 \%$ respectively when water quenched from $1000-1100^{\circ} \mathrm{C}$. A maximum tonnage of crushed basalt of about 850 tons/impact arm is obtained on using manganese steels B2 and B3 toughened from $1000-1100^{\circ} \mathrm{C}$.

The increased efficiency of manganese steels containing Mo and B is attributed to the upgraded strain hardening of the steel matrix. The presence of molybdenum and boron increases the carbon content in solution of austenite and hence increasing its work hardening capacity measured as bulk hardness of the impact arms after service. On the other hand some of $\mathrm{B}, \mathrm{Cr}$ and $\mathrm{Mo}$ strengthen the austenite phase while the other combines with carbon to form secondary carbides which appear in the steel matrix after quenching. These effects contribute to more strength and gouging wear resistance without any loss in impact toughness. It is evident that, the mechanical properties of manganese steel vary with both carbon and manganese content. At carbon level higher than $1.4 \%$ it becomes difficult to retain all the carbon in solution with the austenite even after quench annealing. This in turn increases the volume fraction of grain boundary cementite-type carbides which cause undesirably low values of impact toughness and strength. Manganese is an austenite stabilizer which delays transformation to martensite. At $13-14 \% \mathrm{Mn}$, transformation of austenite at $350^{\circ} \mathrm{C}$ begins only after 45 hours, which ensures the formation of work hardenable clean austenitic matrix.

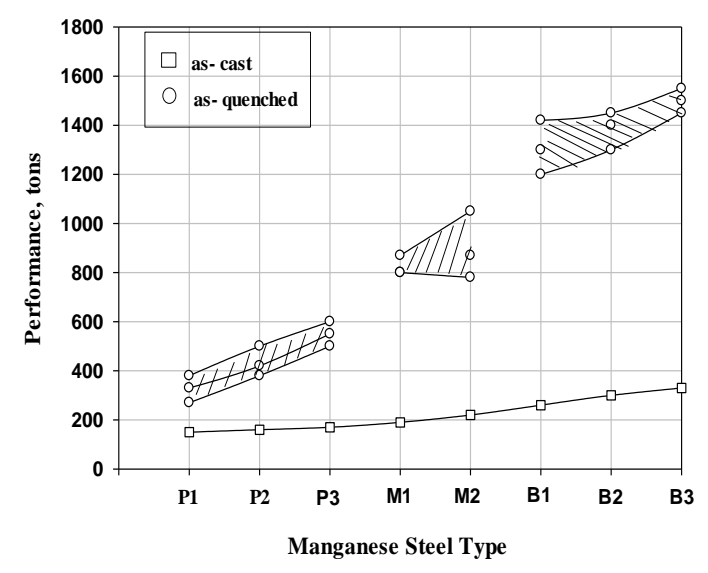

Figure 4: Crushing Effectiveness of Manganese Steels 


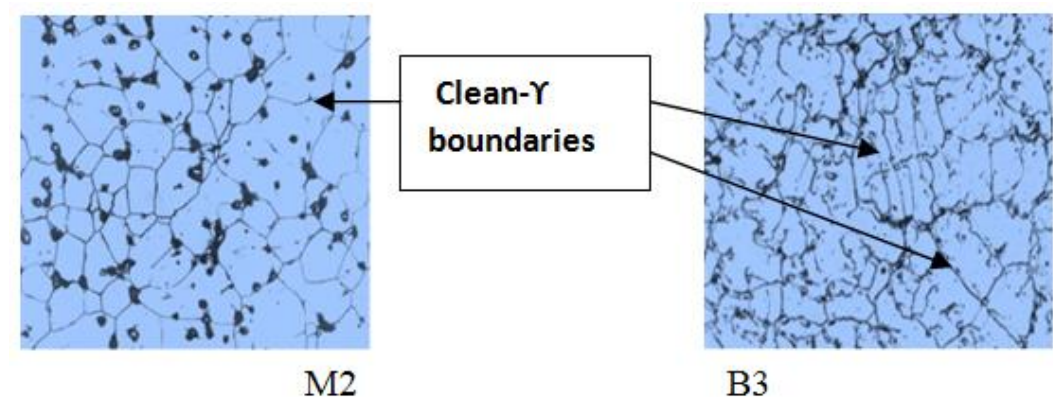

Figure 5: As Water Quenched Microstructures, 100X

\section{WORK HARDENING OF AUSTENITE}

The work hardening capacity of Mn-steel increases as its carbon percentage dissolved in austenite increases. Increase of manganese content to $13 \%$ stabilizes the austenite and the work hardening capacity is only due to formation of high density dislocations. However, addition of Boron to the $13 \% \mathrm{Mn}$ steel alters the mechanism of strain hardening from pure dislocation formation to combined strain-induced marten site formation and hardening by dislocations. Samples of M2 and B3 manganese steel are subjected to repeated X100 impacts using 250kg automatic hammer at fixed travelling height of $0.6 \mathrm{~m}$ and their final measured hardness are found to be 445 and $498 \mathrm{HB}$ respectively. The presence of boron up to $0.37 \%$ in heat B3 enhanced the work hardening not only by increasing the dislocation intensity but by enhancing the formation of induced marten site in the matrix. Figure (6) shows the strain hardening dislocation bands induced in manganese steels M2 and B3. The distribution of dislocations in B3 covers the austenite matrix as a whole, however the dislocation is selective in austenite grains in case of steel M2. However, it is found that boron contributed in strengthening the austenite by some solid solution formation and boron carbide formation (second phase) that results in turn in grain refinement of the whole austenite matrix.

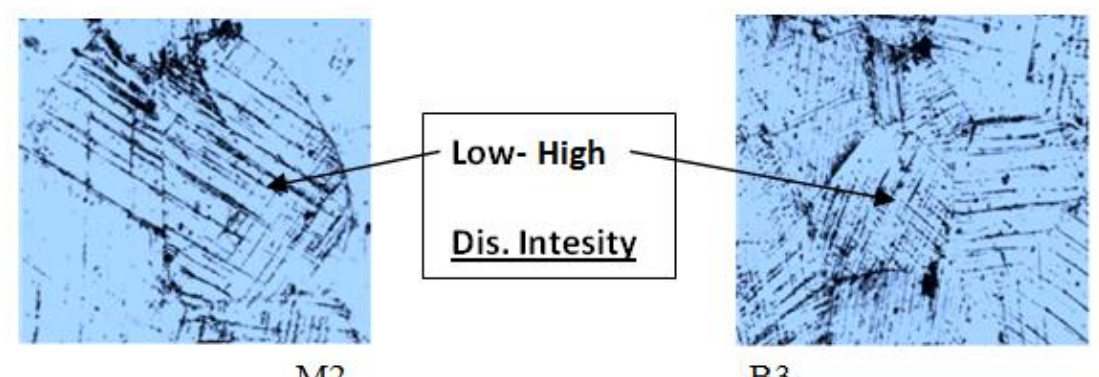

M2

B3

Figure 6: Distribution of Strain Hardening Dislocations, 400X

\section{LOW CYCLIC FATIGUE (LCF)}

The crossings and turnouts of all railways are manufactured from plain Mn-steel due to the ever increasing demand for toughness and resistance to cyclic fatigue. LCF are used to predict the effect of alloying with boron on the life time of impact arms subjected to fatigue under both constant strain or stress amplitudes at room temperature. The strain controlled amplitude are chosen at $0.4,0.5,0.6$ and $1 \%$ that resulted in largest plastic strains. It was found that the number of fatigue cycles in S-N curves for boron-alloyed Mn-steel exceeds 1.4 times that obtained for plain steel in as quenched strained conditions. 


\section{CONCLUSIONS}

From the above mentioned results, the concluding remarks are as follow:

- Addition of boron to molybdenum - chromium alloyed Mn-steel increases the strength and work hardening capacity of its matrix due to precipitation hardening by boron secondary carbides after quenching, stabilization of soluble carbon in austenite and solid solution strengthening.

- Final hardness of about $500 \mathrm{HB}$ is obtained for alloyed quenched compositions after service, as compared with about $250 \mathrm{HB}$ obtained for same as cast compositions.

- Crushing of about 850 tons Basalt/impact arm for manganese steels B2 and B3 toughened from $1000-1100^{\circ} \mathrm{C}$.

- Fatigue strength is also increased by about 1.4 times over that for plain-Mn steel

\section{REFERENCES}

1. Hurricks P.L. "Some Metallurgical Factors Controlling the Abrasive

2. Wear Resistance of Steels", Wear of Metals, Vol. 26, P.285-304, 1975.

3. Borik F., and Scholz W.G. "Gouging Abrasion Test For Materials Used in

4. Ore and Rock Crushing" Journal of Materials, Vol. 6, No. 3, P. 590, 1971.

5. Elzanaty, H. (2014). Effect of different Si content on the mechanical properties in Al-based alloy. International Journal of Research in Engineering \& Technology (IMPACT: IJRET), 2(7), 49-54.

6. "Metals Handbook in Selection of Iron and Steel", Vol. 1, P.568, 1976.

7. Diesburg D.E. and Borik F. "Optimizing Abrasion Resistance and Toughness in Steels \& Iron for the Mining Industry", Symposium for the mining industry, climax molybdenum Co., P. 15, 1974.

8. El-Ghazaly, S.A. and Abbas M.A. "Optimizing the Production Technology of Manganese Steel", Neue Hutte, Vol. 35, No. 9, P. 335-337, 1990.

9. Alavala, C. R. (2016). Effect of Temperature, Strain Rate and Coefficient of Friction on Deep Drawing Process of 6061 Aluminum Alloy. International Journal of Mechanical Engineering, 5(6), 11-24.

10. Steel Castings Handbook", Steel foundries Society of America, P.571,1975.

11. Tsujimoto N. "Casting Practices of Abrasion Resistant Austenitic

12. Manganese Steel". South East Asia Iron \& Steel Institute Quarterly, 10-1978

13. Raghavan a.o. 'Behavior in Hadfield steel.'Trans Metall Soc AIME, Vol75, p.245, 1969.

14. Sharma, S., \& Kini, V. (2018). Effect of heat treatment and mechanical characterization of AISI 4140 steel. International Journal of Mechanical and Production Engineering Research and Development, 8(6), 603-610.

15. J.Gutierrez,D.Raabe "Dislocations and twin substructure evolution during straining $22 \%$ Mn steel" Acta Materialia,vol.59,p.6449,2011

16. C.Efstathiou. H.Sehitoglu "Strain hardening and heterogeous deformation during twinning in Hadfield Steel" Acta Materialia, vol.58, p.1479, 2010 